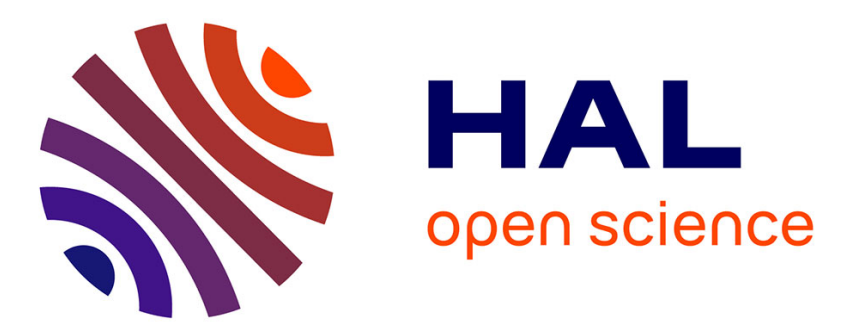

\title{
Rainwater harvesting and groundwater conservation: when endogenous heterogeneity matters
}

Raphael Soubeyran, Mabel Tidball, Agnes Tomini, Katrin Erdlenbruch

\section{To cite this version:}

Raphael Soubeyran, Mabel Tidball, Agnes Tomini, Katrin Erdlenbruch. Rainwater harvesting and groundwater conservation: when endogenous heterogeneity matters. Environmental and Resource Economics, 2015, 62 (1), pp.19-34. 10.1007/s10640-014-9813-9 . hal-01129958

\section{HAL Id: hal-01129958 \\ https://hal.science/hal-01129958}

Submitted on 16 May 2020

HAL is a multi-disciplinary open access archive for the deposit and dissemination of scientific research documents, whether they are published or not. The documents may come from teaching and research institutions in France or abroad, or from public or private research centers.
L'archive ouverte pluridisciplinaire HAL, est destinée au dépôt et à la diffusion de documents scientifiques de niveau recherche, publiés ou non, émanant des établissements d'enseignement et de recherche français ou étrangers, des laboratoires publics ou privés. 


\title{
Rainwater Harvesting and Groundwater Conservation: When Endogenous Heterogeneity Matters
}

\author{
Raphaël Soubeyran*, Mabel Tidball ${ }^{\dagger} \quad$ Agnes Tomini; \\ Katrin Erdlenbruch ${ }^{\S}$
}

\begin{abstract}
In this paper, we focus on resource conservation in a model of decentralized management of groundwater and rainwater. We show that a conservation policy may have opposite effects on the level of the resource, depending on the outcome of the decentralized management. More precisely, we consider identical farmers who can use two water resources (groundwater and/or rainwater) and we study the symmetric and asymmetric feedback stationary Nash equilibria of the dynamic game. We show that a subsidy on the use of rainwater may increase the level of the aquifer at the symmetric equilibrium, whereas it decreases the level of the aquifer at the asymmetric equilibrium. This suggests that the usual focus on (interior) symmetric equilibria in dynamic games may provide misleading policy implications.
\end{abstract}

JEL Classification: Q15, Q25, C72

Keywords: differential game, asymmetric equilibrium, groundwater, rainwater, taxation.

*INRA, UMR1135 LAMETA, F-34000 Montpellier, France; soubeyra@supagro.inra.fr.

${ }^{\dagger}$ INRA, UMR1135 LAMETA, F-34000 Montpellier, France; tidball@supagro.inra.fr.

$\ddagger$ UMR1135 LAMETA, F-34000 Montpellier, France; agnestomini@gmail.com.

§Irstea, UMR G-EAU, F-34196 Montpellier, France; katrin.erdlenbruch@irstea.fr. 


\section{Introduction}

Water scarcity is expected to become an ever-increasing problem in the future and one of the main issues under climate change (IPCC [7]). With the increase in the frequency of extreme weather events, one of the key climate impacts is changing precipitation patterns, which may challenge hydrological functioning, and disturb existing equilibria (IPCC [7]). We can thus expect that the growing pressure on common resources will trigger further competition among resource users, jeopardizing existing management arrangements (Ostrom [15]). The ongoing decline in water tables encourages developing new conservation policies and new water supplies in many places in the World. Scholars argue that pricing schemes may help to conserve water (Johnson et al. [8]) and that rainwater harvesting should be promoted (Pandey [16]). Rainwater harvesting is also put forward by several international organizations' programmes such as the United Nations Environment Programme. In several States, in Europe ${ }^{1}$ and in the U.S., ${ }^{2}$ tax credits are offered in order to reduce the costs of rainwater harvesting.

The present paper has two main contributions. First, whereas the literature on groundwater management has mainly discussed the quantitative effect of a policy on users wealth (see Koundouri [10] for a survey), we focus on the qualitative effect of a policy, that is whether the policy results in a greater, or on the contrary a smaller, conservation level of the groundwater resource. We consider a model of decentralized management of groundwater and rainwater and show that a conservation policy may have opposite effects on the level of the resource, depending on the outcome of the decentralized management. Incentives for rainwater use can lead to an increase or a decrease in the level of the aquifer, because of the lack of coordination as regards groundwater and rainwater use. Second, going beyond the usual focus on symmetric (interior) equilibria in dynamic games, ${ }^{3}$ we

\footnotetext{
${ }^{1}$ In Europe's biggest crop production area, in the center and north of France, where farmers have access to both groundwater and rainwater resources, water taxes are differentiated such that rainwater use is relatively less expensive than groundwater use. This policy aims at preserving groundwater resources and is intended to be strengthened over the next couple of years, with increasing differences in tax rates being scheduled (see 10th Programme of the Seine-Normandie Water Agency).

${ }^{2}$ See, for instance, the Texas Tax Code 152.355.

${ }^{3}$ Dockner et al. [4] argue that "one can often take advantage of symmetries. For example if the game is completely symmetric [...] one can try to find a symmetric Nash equilibrium". Rowat [20] uses computational techniques to identify the Markov perfect equilibria in a two symmetric agent differential game with bounded controls. He finds no evidence of asymmetric equilibria. However he focuses on linear
} 
characterize the stationary symmetric and asymmetric (feedback) Nash equilibria of the dynamic game played by groundwater and rainwater users. We show that a subsidy (a tax) on the use of rainwater may increase (decrease) the level of the aquifer at a symmetric equilibrium, whereas the subsidy (the tax) may decrease (increase) the level of the aquifer at an asymmetric equilibrium. This suggests that the usual focus on (interior) symmetric equilibria in dynamic games may provide misleading policy implications.

In our model, we deal with the interactions between identical farmers who can choose between two water supplies (groundwater or rainwater). First, groundwater and rainwater have different productive properties: evaporation of rainwater may be greater than that of groundwater, and the consumption of groundwater may consequently be higher; groundwater may be salty or contain toxic substances (e.g. chloride, nitrates, pesticides) leading to higher consumption of rainwater. Second, groundwater and rainwater are interdependent, because the collection of rainwater reduces the amount of water that replenishes the aquifer. An interesting property of this game is that the farmers who collect rainwater escape the pumping cost externality, but they generate a negative externality for the farmers who pump groundwater: they reduce the amount of water that can replenish the aquifer which, in turn, increases the pumping cost.

This paper builds on the literature on water resource economics (see for example Cummings [3], Gisser and Sanchez [6], Moreaux and Reynaud [12],[13], Negri [14], RosetaPalma [18], Rubio and Casino [21]). In particular, our paper is linked to the literature that considers water as a system of different water bodies. One strand of the literature deals with optimal management of multiple groundwater resources (see Roumasset and Wada [19] or Zeitouni and Dinar [26]). Another strand studies the conjunctive use of ground and surface water (see Burt [1], Chakravorty and Umetsu [2], Gemma and Tsur [5], Knapp and Olson [9], Krulce, Roumasset and Wilon [11], Pongkijvorasin and Roumasset [17], Stahn and Tomini [23], [24] or Tsur and Graham-Tomasi [25]). Roumasset and Wada [19] showed that optimal management of several independent groundwater resources depend on their marginal opportunity cost: only the resource with the lowest marginal opportunity cost is used initially, whereas in the steady state, all resources are used. However, in the present paper, we consider two interrelated resources. Hence, we cannot simply compare quadratic differential games and interior solutions. 
marginal extraction and user costs of separate use, but we compare conjunctive and separate use of groundwater and rainwater. Zeitouni and Dinar [26] studied the case of two interrelated aquifers: depending on the relative height of the water tables, water will flow from one aquifer to the other. This could lead to the contamination of the aquifer with the better water quality. Optimal water management is then defined by the joint management of these interrelated resources, the threat of contamination representing an additional externality that has to be taken into account. In the present paper, we do not deal with two interrelated aquifers but instead with the interaction between rainwater and groundwater resources. Rainwater and groundwater are physically linked because rainwater (partially) infiltrates the soil and replenishes the aquifer. Stahn and Tomini ([23], [24]) also considered the joint use of groundwater and rainwater and focused on the optimal management of these resources. They showed that, in the long-run, the introduction of rainwater harvesting may lead to a greater depletion of the groundwater aquifer. This result was obtained by extending the standard groundwater model to include the connection between two water supplies. Especially, in [23], the decrease in the water table first occurs because of the negative effect of rainwater harvesting on the groundwater recharge rate and, second, because the efficiency of water use depends on the relative rate of evapotranspiration in the storage reservoir and infiltration to the groundwater aquifer. In the present paper, we consider groundwater and rainwater uses but, in contrast to Stahn and Tomini ([23], [24]), we focus on interactions between several farmers. In this context, the literature has shown that the cost-externality and the strategic externality have to be taken into account when regulatory policies are designed (see Negri [14] and Rubio and Casino [21]). We build on this fact and highlight the qualitative effect that a conservation policy may have.

The paper is organized as follows. In section 2, we present the model. In section 3 , we describe the necessary conditions required for the existence of stationary symmetric and asymmetric feedback Nash equilibria, emphasizing the interactions between the two water sources. In section 4, we discuss the impact of water-pricing policies (tax/subsidy) on the rainwater and groundwater extraction policies in the symmetric and asymmetric feedback Nash equilibria. Finally, in section 5, we draw some conclusions. 


\section{The Model}

We consider a continuous time strategic interaction problem where a fixed number $N \geq 2$ of farmers uses water as an input and can use rainwater and/or groundwater.

\subsection{Groundwater Dynamics}

We consider a single aquifer. The water table of this aquifer increases because some part of rain - the one that is not collected for irrigation purposes - soaks into the soil at rate of infiltration $\rho \in(0,1)$. We denote $R$ the quantity of rain. In line with the wider part of literature, ${ }^{4}$ the natural recharge is exogenously determined (i.e. not stock dependent). ${ }^{5}$ Conversely, the water table decreases because farmers withdraw water from the ground.

Farmer $i$ pumps a quantity of groundwater $w_{g i}(t)$ from the aquifer at time $t$ and therefore the decline of the level of water table results from the total pumping : $\sum_{i=1}^{N} w_{g i}(t)$. He can also directly collect a quantity $w_{r i}(t)$ from the recharge at the surface, before rainwater seeps into the ground. Consequently, rainwater harvesting reduces the amount of water that replenishes the aquifer by the total quantity of rainwater that resource users have harvested, that is $\sum_{i=1}^{N} w_{r i}(t)$. This quantity cannot exceed the quantity of rain, i.e. $\sum_{i=1}^{N} w_{r i}(t) \leq R$. When the farmers collect rainwater, the quantity of water that reaches the aquifer is $\rho\left(R-\sum_{i=1}^{N} w_{r i}(t)\right)$.

Combining these assumptions all together, we assume that the groundwater dynamics is characterized by the following differential equation:

$$
\dot{h}=\rho\left(R-\sum_{i=1}^{N} w_{r i}(t)\right)-\sum_{i=1}^{N} w_{g i}(t),
$$

where $h(t)$ is the level of the water table at time $t$.

This simple formulation allows us to account for the connection between the two water supplies and emphasizes the hydrological aspect.

\footnotetext{
${ }^{4}$ See, among others, Gisser and Sanchez [6], Koundouri [10], Rubio and Casino [22].

${ }^{5}$ For simplification, we do not take into account the local percolation and discharge. When the water table is near the ground surface, there is little opportunity for recharge and shallow aquifers are recharged by local percolation of surface water and discharged by crops that use the water out of the ground. However, large aquifers run deep and are highly dependent on rain and melting snow.
} 


\section{$2.2 \quad$ Farmers' Net Benefits}

Farmers use a combination of the two water supplies, $w_{g i}(t) \geq 0$ and $w_{r i}(t) \geq 0$ at period $t$, for production. ${ }^{6}$ The two water supplies have heterogeneous productive properties, thus they impact the output differently. Namely, the productivity of groundwater is denoted $\mu>0$ and the productivity of rainwater is denoted $\theta>0$. We assume that the two water supplies are substitutes:

$$
w_{i}=\mu w_{g i}+\theta w_{r i}
$$

The effective quantity of water, $w_{i}$, is the unique input and $F($.$) is an increasing and$ concave production function. The price of one unit of output is normalized to 1 , thus $F\left(w_{i}\right)$ ) represents farmer $i$ 's instantaneous benefit. The cost of extraction of groundwater, $C_{g}(.,$.$) , is a function of the water table level, h$, and of the individual pumping rate, $w_{g}{ }^{7}$ This cost increases with the quantity of groundwater extraction and decreases with the water table level:

$$
\frac{\partial C_{g}}{\partial w_{g}}\left(h, w_{g i}\right) \geq 0, \quad \frac{\partial C_{g}}{\partial h}\left(h, w_{g i}\right) \leq 0 .
$$

The cost of rainwater harvesting, $C_{r}\left(w_{r i}\right)$, (e.g the transport cost from the point of the reservoir to the irrigation area) depends on the quantity collected and does not depend on the level of the water table. This cost is increasing, $C_{r}^{\prime}>0$. We make usual assumptions on the convexity of the cost functions, $\frac{\partial^{2} C_{g}}{\partial w_{g}^{2}}\left(h, w_{g i}\right) \geq 0, \frac{\partial^{2} C_{g}}{\partial h^{2}}\left(h, w_{g i}\right) \geq 0$, and $C_{r}^{\prime \prime}\left(w_{r i}\right) \geq 0$. We also assume that the cross-derivative of the cost of groundwater extraction is negative, $\frac{\partial^{2} C_{g}}{\partial h \partial w_{g}}\left(h, w_{g i}\right)<0$, i.e. the marginal cost of groundwater extraction decreases when the level of the water table increases.

The combination of all these observations leads to define farmer $i$ 's net benefit at time $t$ as follows:

$$
F\left(\mu w_{g i}(t)+\theta w_{r i}(t)\right)-C_{g}\left(h(t), w_{g i}(t)\right)-C_{r}\left(w_{r i}(t)\right) .
$$

The farmers behave non-cooperatively. They maximize the present value of their stream of profits given the extraction path of others with a common discount rate $\delta$. The $i$ th farmer faces the following dynamic optimization problem:

\footnotetext{
${ }^{6}$ As we focus on irrigation strategies, water is the only input considered.

${ }^{7}$ We consider a "bathtub" type aquifer, and then the cost is the same at each point of the aquifer.
} 


$$
\begin{aligned}
& \max _{\left\{w_{g i}, w_{r i}\right\}} \int_{0}^{\infty}\left(F\left(w_{i}(t)\right)-C_{g}\left(h(t), w_{g i}(t)\right)-C_{r}\left(w_{r i}(t)\right)\right) \exp ^{-\delta t} d t \\
& \qquad \begin{array}{l}
\dot{h}=\rho\left(R-\sum_{i}^{N} w_{r i}(t)\right)-\sum_{i}^{N} w_{g i}(t) \\
w_{g i}(t) \geq 0 \\
w_{r i}(t) \geq 0 \\
h(t) \geq 0 \\
R \geq \sum_{i}^{N} w_{r i}(t) \\
h(0) \quad \text { given and } h(\infty) \quad \text { free }
\end{array}
\end{aligned}
$$

In the next section, we will focus on the stationary feedback Nash equilibria of this differential game.

\section{Stationary Feedback Nash Equilibria}

The farmers solve their dynamic problem simultaneously. We focus on the Stationary (feedback) Nash Equilibria (SNE). In other words, assuming that players use Markovian strategies, we have $w_{r j}(t)=\phi_{r j}(h(t))$ and $w_{g j}(t)=\phi_{g j}(h(t))$ for all $j$, and we can define the current-value Hamiltonian function of farmer $i$ as follows: ${ }^{8}$

$$
H_{i}=F\left(w_{i}\right)-C_{g}\left(h, w_{g i}\right)-C_{r}\left(w_{r i}\right)+p_{i}\left[\rho\left(R-w_{r i}-\sum_{j \neq i} \phi_{r j}(h)\right)-w_{g i}-\sum_{j \neq i} \phi_{g j}(h)\right],
$$

where $p_{i}$ is the shadow price of groundwater for farmer $i$.

We consider cases where the aquifer is not fully exhausted, $h(t)>0$. We also focus on the most interesting cases in which some farmers pump groundwater at the SNE. This means that some strictly positive quantity of rain has to soak into the soil, i.e. $\sum_{i=1}^{N} w_{r i}(t)<R$. The Lagrangian function of farmer $i$ is then:

$$
L_{i}=H_{i}+\lambda_{g i} w_{g i}+\lambda_{r i} w_{r i}
$$

\footnotetext{
${ }^{8}$ We remove the argument $t$ to relieve the expressions.
} 
where $\lambda_{g i}$ and $\lambda_{r i}$ are the Lagrangian multipliers.

The first order conditions for farmer $i$ are:

$$
\begin{aligned}
\frac{\partial L_{i}}{\partial w_{g i}} & =\mu F^{\prime}\left(w_{i}\right)-\frac{\partial C_{g}}{\partial w_{g}}\left(h, w_{g i}\right)-p_{i}+\lambda_{g i}=0, \\
\lambda_{g i} & \geq 0, \quad \lambda_{g i} w_{g i}=0, \\
\frac{\partial L_{i}}{\partial w_{r i}} & =\theta F^{\prime}\left(w_{i}\right)-C_{r}^{\prime}\left(w_{r i}\right)-\rho p_{i}+\lambda_{r i}=0, \\
\lambda_{r i} & \geq 0, \quad \lambda_{r i} w_{r i}=0, \\
\dot{p}_{i} & =\delta_{i}(h) p_{i}-\frac{\partial L_{i}}{\partial h}=\delta_{i}(h) p_{i}+\frac{\partial C_{g}}{\partial h}\left(h, w_{g i}\right), \\
\dot{h} & =\rho R-\left(\rho w_{r i}+w_{g i}\right)-\sum_{j \neq i}\left[\rho \phi_{r j}(h)+\phi_{g j}(h)\right],
\end{aligned}
$$

where $w_{i}=\mu w_{g i}+\theta w_{r i}$ and, $\delta_{i}(h)$ is such that

$$
\delta_{i}(h)=\delta+\sum_{j \neq i}\left(\rho \frac{\partial \phi_{r j}}{\partial h}+\frac{\partial \phi_{g j}}{\partial h}\right) .
$$

Condition (8) states that the marginal benefit of one additional unit of groundwater must be equal to the total marginal cost (that is the sum of costs, extraction or storage, with the opportunity cost of removing one unit of water from the ground), if the farmers indeed use groundwater. Condition (10) states that the marginal benefit of one additional unit of rainwater must be equal to the total marginal cost (that is the sum of costs, extraction or storage, with the opportunity cost of removing one unit of water from the ground), if the farmers indeed use rainwater. Condition (12) characterizes the time variation of shadow price of player $i, p_{i}$. This condition characterizes the effect of a decrease of the water table level (in the current period) on future profits. It is positively affected by the effective discount rate, the current price and the marginal effect of the water table depletion on pumping cost. Conditions (9) and (11) are the complementary slackness conditions. Condition (14) defines the effective discount rate, which is the rate at which agent $i$ discounts the future value of the resource. It is composed with the sum of the discount rate, $\delta$, and an additional term, $\sum_{j \neq i}\left(\rho \frac{\partial \phi_{r j}}{\partial h}+\frac{\partial \phi_{g j}}{\partial h}\right)$. The intuition behind this additional term is that, when farmers use feedback strategies, they take into account the 
fact that their current use of water will affect other farmers' future use of water (through a change in the height of the watertable). This can be interpreted as a change of the discount rate used in the dynamics of the farmer's shadow price. ${ }^{9}$

In the following, the marginal costs of groundwater and rainwater play an important role in the optimal choice of the farmers. The marginal costs of groundwater and rainwater are essentially different because the short run marginal cost of groundwater, $\frac{\partial C_{g}}{\partial w_{g}}\left(h, w_{g i}\right)$, depends on the level of the water table $h$ while the short run marginal cost of rainwater, $C_{r}^{\prime}\left(w_{r i}\right)$, does not. In a SNE, the shadow price of groundwater becomes constant and is given by $p_{i}=-\frac{1}{\delta_{i}(h)} \frac{\partial C_{g}}{\partial h}\left(h, w_{g i}\right)$. It is the marginal effect of a decrease in the water table weighted by the effective discount rate $\delta_{i}(h)$ (see condition (12) with $\dot{p}_{i}=0$ ). It represents the increase in the future marginal costs of groundwater use due to contemporaneous use of groundwater. The user cost of rainwater, $\rho p_{i}$, is a fraction of the user cost of groundwater, because the recharge rate of the aquifer from rainwater is $\rho<1$. It represents the increase in the future marginal costs of groundwater use due to contemporaneous use of rainwater.

Let us define the marginal cost of groundwater of farmer $i$. It is the sum of the marginal extraction cost, $\frac{\partial C_{g}}{\partial w_{g}}\left(h, w_{g i}\right)$, and the user cost of groundwater, $p_{i}=-\frac{1}{\delta_{i}(h)} \frac{\partial C_{g}}{\partial h}\left(h, w_{g i}\right)$ :

$$
\frac{\partial C_{g}}{\partial w_{g}}\left(h, w_{g i}\right)-\frac{1}{\delta_{i}(h)} \frac{\partial C_{g}}{\partial h}\left(h, w_{g i}\right),
$$

Similarly, we define the marginal cost of rainwater of farmer $i$ It is the sum of the marginal harvesting cost $C_{r}^{\prime}\left(w_{r i}\right)$ and the user cost of rainwater, $\rho p_{i}=-\rho \frac{1}{\delta_{i}(h)} \frac{\partial C_{g}}{\partial h}\left(h, w_{g i}\right)$ :

$$
C_{r}^{\prime}\left(w_{r i}\right)-\rho \frac{1}{\delta_{i}(h)} \frac{\partial C_{g}}{\partial h}\left(h, w_{g i}\right)
$$

Let us also define the ratio of marginal costs as the ratio of the marginal cost of ground-

\footnotetext{
${ }^{9}$ Assume that the other farmers increase their use of groundwater and rainwater when the height of the watertable increases, i.e. $\sum_{j \neq i}\left(\rho \frac{\partial \phi_{r j}}{\partial h}+\frac{\partial \phi_{g j}}{\partial h}\right)$, and $p_{i}>0$. Hence, the shadow price of groundwater for farmer $i$ may be increasing (see necessary condition (12)). In such a situation, farmer $i$ has incentives to increase its use of groundwater and rainwater.
} 
water and the marginal cost of rainwater:

$$
\frac{\frac{\partial C_{g}}{\partial w_{g}}\left(h, w_{g i}\right)-\frac{1}{\delta_{i}(h)} \frac{\partial C_{g}}{\partial h}\left(h, w_{g i}\right)}{C_{r}^{\prime}\left(w_{r i}\right)-\rho \frac{1}{\delta_{i}(h)} \frac{\partial C_{g}}{\partial h}\left(h, w_{g i}\right)} .
$$

At the SNE, farmers may choose various mixes of groundwater and rainwater. In particular, they can use groundwater or rainwater only but they can also use both water sources simultaneously.

\subsection{Symmetric and Asymmetric SNE}

To characterize the various possible types of SNE, it is convenient to define three different groups of farmers: (i) $n_{g} \geq 0$ farmers are fully specialized in groundwater pumping (group $G$ ), (ii) $n_{r} \geq 0$ farmers are fully specialized in rainwater harvesting (group $R$ ), and (ii) $n_{b} \geq 0$ farmers use both groundwater and rainwater (group $B$ ).

We are going to consider symmetric and asymmetric SNE. Symmetric SNE are such that all the farmers use the same quantity of rainwater and/or groundwater, i.e. such that $w_{r i}=w_{r j}$ and $w_{g i}=w_{g j}$ for all $i$ and $j$. Asymmetric equilibria are such at least two farmers do not use the same quantity of rainwater and/or groundwater, i.e. $w_{r i} \neq w_{r j}$ or $w_{g i} \neq w_{g j}$. Notice that if at least two groups of farmers (among $G, R$ and $B$ ) are non empty, then the SNE is necessarily asymmetric.

We distinguish the first order conditions for the three groups of farmers. Formally, the optimal choice of a farmer who uses groundwater only, i.e. $w_{r i}=0$ and $w_{g i}>0$ with $i \in G$, is characterized by the following necessary conditions (with the slackness condition, $\left.\lambda_{g i}=0\right)$, for all $i \in G$,

$$
\begin{aligned}
& \mu F^{\prime}\left(\mu w_{g i}\right)-\frac{\partial C_{g}}{\partial w_{g}}\left(h, w_{g i}\right)-p_{i}=0, \\
& \theta F^{\prime}\left(\mu w_{g i}\right)-C_{r}^{\prime}(0)-\rho p_{i}(t)+\lambda_{r i}=0, \\
& \dot{p}_{i}=0=\delta_{i}(h) p_{i}+\frac{\partial C_{g}}{\partial h}\left(h, w_{g i}\right) .
\end{aligned}
$$

A farmer who uses rainwater only, i.e. $w_{r i}>0$ and $w_{g i}=0$ with $i \in R$, is characterized 
by the following necessary conditions (with the slackness condition, $\lambda_{r i}=0$ ), for all $i \in R$,

$$
\begin{aligned}
& \mu F^{\prime}\left(\theta w_{r i}\right)-\frac{\partial C_{g}}{\partial w_{g}}(h, 0)-p_{i}+\lambda_{g i}=0, \\
& \theta F^{\prime}\left(\theta w_{r i}\right)-C_{r}^{\prime}\left(w_{r i}\right)-\rho p_{i}=0, \\
& \dot{p}_{i}=0=\delta_{i}(h) p_{i}+\frac{\partial C_{g}}{\partial h}(h, 0),
\end{aligned}
$$

The choice of a farmer who uses both rainwater and groundwater, i.e. $w_{r i}>0$ and $w_{g i}>0$ with $i \in B$, is characterized by the following necessary conditions (with the two slackness conditions, $\lambda_{r i}=\lambda_{g i}=0$ ), for all $i \in B$,

$$
\begin{aligned}
& \mu F^{\prime}\left(\mu w_{g i}+\theta w_{r i}\right)-\frac{\partial C_{g}}{\partial w_{g}}\left(h, w_{g i}\right)-p_{i}=0, \\
& \theta F^{\prime}\left(\mu w_{g i}+\theta w_{r i}\right)-C_{r}^{\prime}\left(w_{r i}\right)-\rho p_{i}=0, \\
& \dot{p}_{i}=0 \Leftrightarrow \delta_{i}(h) p_{i}+\frac{\partial C_{g}}{\partial h}\left(h, w_{g i}\right)=0
\end{aligned}
$$

Finally, the water table dynamics is affected by the resource use of all the farmers. At any stationary equilibrium, using (13), we have:

$$
\dot{h}=0 \Leftrightarrow \rho R-\sum_{i \in R} \rho w_{r i}-\sum_{i \in G} w_{g i}-\sum_{i \in B}\left(\rho w_{r i}+w_{g i}\right)=0 .
$$

\subsection{Productivity and Irrigation Strategies}

Let us further analyze the necessary conditions for each group of farmer.

Let us consider a farmer $i$ of group $G$ (the farmers who use groundwater only). Using equations (18) and (20), we find that the marginal benefit of groundwater must be equal to the marginal cost of groundwater:

$$
\mu F^{\prime}\left(\mu w_{g i}\right)=\frac{\partial C_{g}}{\partial w_{g}}\left(h, w_{g i}\right)-\frac{1}{\delta_{i}(h)} \frac{\partial C_{g}}{\partial h}\left(h, w_{g i}\right),
$$

and using condition (19) and $\lambda_{r i} \geq 0$, we find that the marginal cost of rainwater must 
be larger than the marginal benefit of rainwater:

$$
C_{r}^{\prime}(0)-\rho \frac{1}{\delta_{i}(h)} \frac{\partial C_{g}}{\partial h}\left(h, w_{g i}\right) \geq \theta F^{\prime}\left(\mu w_{g i}\right) .
$$

Using (28) and (29), we obtain the following necessary condition for the choice of the group who uses groundwater only (for $i \in G$ ):

$$
\frac{\mu}{\theta} \geq \frac{\frac{\partial C_{g}}{\partial w_{g}}\left(h, w_{g i}\right)-\frac{1}{\delta_{i}(h)} \frac{\partial C_{g}}{\partial h}\left(h, w_{g i}\right)}{C_{r}^{\prime}(0)-\rho \frac{1}{\delta_{i}(h)} \frac{\partial C_{g}}{\partial h}\left(h, w_{g i}\right)} .
$$

Condition (30) states that, for any farmer who uses groundwater only, the relative marginal productivity of groundwater is larger than the ratio of marginal costs.

Let us consider a farmer who uses rainwater only $(i \in R)$. Using (22) and (23), we find that the marginal benefit of rainwater must equal its marginal cost:

$$
\theta F^{\prime}\left(\theta w_{r i}\right)=C_{r}^{\prime}\left(w_{r i}\right)-\rho \frac{1}{\delta_{i}(h)} \frac{\partial C_{g}}{\partial h}(h, 0)
$$

and using (21), (23), and $\lambda_{g i} \geq 0$, we find that the marginal cost of groundwater must be greater than or equal to its marginal benefit:

$$
\mu F^{\prime}\left(\theta w_{r i}\right) \leq \frac{\partial C_{g}}{\partial w_{g}}(h, 0)-\frac{1}{\delta_{i}(h)} \frac{\partial C_{g}}{\partial h}(h, 0)
$$

Using conditions (31) and (32), we obtain a necessary condition for the choice of the group who uses rainwater only (for $i \in R$ ):

$$
\frac{\mu}{\theta} \leq \frac{\frac{\partial C_{g}}{\partial w_{g}}(h, 0)-\frac{1}{\delta_{i}(h)} \frac{\partial C_{g}}{\partial h}(h, 0)}{C_{r}^{\prime}\left(w_{r i}\right)-\rho \frac{1}{\delta_{i}(h)} \frac{\partial C_{g}}{\partial h}(h, 0)} .
$$

Condition (33) states that, for any farmer who uses rainwater only, the productivity ratio has to be smaller than the ratio of marginal costs.

Let us now consider a farmer who uses both groundwater and rainwater $(i \in B)$. Using 
conditions (24), (25) and (26), we obtain the following necessary condition (for $i \in B$ ):

$$
\frac{\mu}{\theta}=\frac{\frac{\partial C_{g}}{\partial w_{g}}\left(h, w_{g i}\right)-\frac{1}{\delta_{i}(h)} \frac{\partial C_{g}}{\partial h}\left(h, w_{g i}\right)}{C_{r}^{\prime}\left(w_{r i}\right)-\rho \frac{1}{\delta_{i}(h)} \frac{\partial C_{g}}{\partial h}\left(h, w_{g i}\right)} .
$$

Condition (34) states that the farmers of group $B$ must be indifferent between using rainwater or groundwater: the relative productivity must be equal to the ratio of the marginal costs.

We distinguish three types of SNE in which some farmers may be specialized and other not. The following proposition provides a necessary condition for the existence of a SNE in which all the farmers are specialized:

Proposition 1 (Specialized) In a SNE with specialized farmers, no farmer use both rainwater and groundwater $\left(n_{b}=0\right)$, some farmers use groundwater only $\left(n_{g} \geq 0\right)$ and some farmers use rainwater only $\left(n_{r} \geq 0\right)$. A necessary condition for such an SNE is:

$$
\frac{\frac{\partial C_{g}}{\partial w_{g}}\left(h, w_{g i}\right)-\frac{1}{\delta_{i}(h)} \frac{\partial C_{g}}{\partial h}\left(h, w_{g i}\right)}{C_{r}^{\prime}(0)-\rho \frac{1}{\delta_{i}(h)} \frac{\partial C_{g}}{\partial h}\left(h, w_{g i}\right)} \leq \frac{\mu}{\theta} \leq \frac{\frac{\partial C_{g}}{\partial w_{g}}(h, 0)-\frac{1}{\delta_{j}(h)} \frac{\partial C_{g}}{\partial h}(h, 0)}{C_{r}^{\prime}\left(w_{r j}\right)-\rho \frac{1}{\delta_{j}(h)} \frac{\partial C_{g}}{\partial h}(h, 0)},
$$

for all $i \in G$ and all $j \in R$.

Proposition 1 states that, a SNE in which all the farmers are specialized exists only if the productivity ratio is larger that the ratio of the marginal costs of farmers who use groundwater only and smaller than the ratio of the marginal costs of farmers who use rainwater only. This is possible for two reasons. First, since farmers use feedback strategies, two farmers $i$ and $j$ may have different effective discount rates, $\delta_{i}(h)$ and $\delta_{j}(h)$. Hence, their ratios of marginal costs may be two different functions. Second, the ratio of the marginal costs of a farmer is decreasing in $w_{r}$ and may also be decreasing in $w_{g} \cdot{ }^{10}$ Hence, even if the marginal cost functions of all the farmers are identical, a SNE with specialized farmers may still exist.

The second type of SNE is such that farmers are not specialized, i.e. they use groundwater and rainwater. The following proposition provides a necessary condition for the existence of such a SNE:

\footnotetext{
${ }^{10}$ See the proof of Proposition 4.
} 
Proposition 2 (Non Specialized) In a SNE with non specialized farmers, all the farmers use both rainwater and groundwater $\left(n_{b}>0\right.$ and $\left.n_{g}=n_{r}=0\right)$. A necessary condition for such a SNE is:

$$
\frac{\mu}{\theta}=\frac{\frac{\partial C_{g}}{\partial w_{g}}\left(h, w_{g i}\right)-\frac{1}{\delta_{i}(h)} \frac{\partial C_{g}}{\partial h}\left(h, w_{g i}\right)}{C_{r}^{\prime}\left(w_{r i}\right)-\rho \frac{1}{\delta_{i}(h)} \frac{\partial C_{g}}{\partial h}\left(h, w_{g i}\right)}, \forall i
$$

Proposition 2 states that, a SNE in which all the farmers use both groundwater and rainwater exists only if the productivity ratio equals the ratio of the marginal costs of each farmer.

Proposition 3 (Mixed) In a SNE with non specialized and specialized farmers, some farmers use both rainwater and groundwater $\left(n_{b}>0\right)$ and some farmers use rainwater only or groundwater only $\left(n_{r}>0\right.$ and/or $\left.n_{g}>0\right)$. A necessary condition for such an SNE is:

$$
\begin{aligned}
\frac{\frac{\partial C_{g}}{\partial w_{g}}\left(h, w_{g i}\right)-\frac{1}{\delta_{i}(h)} \frac{\partial C_{g}}{\partial h}\left(h, w_{g i}\right)}{C_{r}^{\prime}(0)-\rho \frac{1}{\delta_{i}(h)} \frac{\partial C_{g}}{\partial h}\left(h, w_{g i}\right)} & \leq \frac{\mu}{\theta}=\frac{\frac{\partial C_{g}}{\partial w_{g}}\left(h, w_{g k}\right)-\frac{1}{\delta_{k}(h)} \frac{\partial C_{g}}{\partial h}\left(h, w_{g k}\right)}{C_{r}^{\prime}\left(w_{r k}\right)-\rho \frac{1}{\delta_{k}(h)} \frac{\partial C_{g}}{\partial h}\left(h, w_{g k}\right)} \\
& \leq \frac{\frac{\partial C_{g}}{\partial w_{g}}(h, 0)-\frac{1}{\delta_{j}(h)} \frac{\partial C_{g}}{\partial h}(h, 0)}{C_{r}^{\prime}\left(w_{r j}\right)-\rho \frac{1}{\delta_{j}(h)} \frac{\partial C_{g}}{\partial h}(h, 0)},
\end{aligned}
$$

for all $i \in G$, all $k \in B$ and all $j \in R$.

Proposition 3 states that a SNE in which some farmers are specialized while others are not exists only if the productivity ratio is larger that the ratio of the marginal costs of the farmers who use groundwater only, equals the ratio of the marginal costs of the farmers who use both groundwater and rainwater, and is smaller than the ratio of the marginal costs of the farmers who use rainwater only. This is possible because two farmers may have different ratios of marginal cost and also because the marginal cost function of a farmer is decreasing in $w_{r}$ and may be decreasing and increasing in $w_{g}$.

In the following, we will focus on the symmetric SNE in which farmers are not specialized (the most commonly studied) and the asymmetric SNE in which farmers are specialized (the other polar case). 


\section{Tax/Subsidy on Rainwater Use}

In this section, we investigate the impact of water pricing policies on the use of groundwater and rainwater. Water pricing is used in order to render resource use more efficient and to allocate resources among different uses.

When there is only one resource, one could imagine a tax on water use, in order to keep more water in rivers and protect associated aquatic ecosystems. However, when substitute resources exist, one may want to subsidize rainwater use in order to save groundwater, which may in turn increase the level of the aquifer.

Our model can provide some insight on the effect of such a policy. To do so, we compare the effect of a change in the cost of rainwater use at two different SNE: an asymmetric SNE with specialized farmers who either use groundwater $\left(w_{g}^{A}\right)$ or rainwater $\left(w_{r}^{A}\right)$ (not both), and a symmetric SNE with non specialized farmers who use both groundwater and rainwater $\left(w_{g}^{S}\right.$ and $\left.w_{r}^{S}\right)$. Let $h^{A}$ be the level of the aquifer at the asymmetric SNE, and $h^{S}$ the level of the aquifer at the symmetric SNE.

Let $\sigma$ be the tax level such that the cost of rainwater is $(1+\sigma) C_{r}\left(w_{r}\right)$. If $\sigma>0$, it is a tax and, if $\sigma<0$, it is a subsidy. A decrease in $\sigma$ can be interpreted as an increase in the subsidy level or as a decrease in the tax on rainwater use.

To asses the effect of a change in the policy (a change in $\sigma$ ), we consider a simple linear-quadratic specification of our general model with two farmers. Let us assume that the production function of each farmer is given by $F\left(w_{i}\right)=w_{i}-\frac{1}{2}\left(w_{i}\right)^{2}$, that the cost functions are such that $C_{g}\left(h, w_{g}\right)=(c-h) w_{g}$ with $c>0$ and $C_{r}\left(w_{r}\right)=K w_{r}$. To avoid unrealistic cases in which the net benefit is always decreasing in the amount of rainwater used, we assume that $\theta>K$, i.e. the marginal contribution of rainwater in the production process must be higher than its marginal cost.

We first show that, when farmers are specialized (one farmer uses rainwater only and the other one uses groundwater only), a subsidy on rainwater use (to be precise, a decrease in $\sigma$ ) has the following effect: ${ }^{11}$

\footnotetext{
${ }^{11}$ In the appendix, we show that the two first statements (a decrease in the cost of rainwater use increases rainwater use and decreases groundwater use) can be extended to the case of the general model. The third statement can be generalized to the case of the general model if $n_{g}=1$. See the proof of Proposition 4 in Appendix.
} 
Proposition 4 At the asymmetric SNE with specialized farmers, the introduction of a subsidy on rainwater use (a decrease in $\sigma$ ), increases rainwater use, decreases groundwater use, and decreases the level of the aquifer. Conversely, the introduction of a tax on rainwater use (an increase in $\sigma$ ), decreases rainwater use, increases groundwater use, and increases the level of the aquifer. Formally,

$$
\frac{\partial w_{r}^{A}}{\partial \sigma}<0<\frac{\partial w_{g}^{A}}{\partial \sigma} \text { and } \frac{\partial h^{A}}{\partial \sigma}>0
$$

Proof of Proposition 4: The proof is relegated to the Appendix.

At the asymmetric SNE with specialized farmers, an increase in the subsidy on rainwater (which is equivalent to a decrease in its cost) increases the use of rainwater (for the farmer who uses rainwater only) and decreases the use of groundwater (for the farmer who uses groundwater only). This is consistent with an increase in the cost of groundwater and to a decrease in the level of the aquifer.

Let us now consider the case of non specialized farmers (the two farmers use groundwater and rainwater):

Proposition 5 : At the symmetric SNE with non specialized farmers, the introduction of a subsidy on rainwater use (a decrease in $\sigma$ ), decreases rainwater use, increases groundwater use, and increases the level of the aquifer. Conversely, the introduction of a tax on rainwater use (an increase in $\sigma$ ), increases rainwater use, decreases groundwater use, and decreases the level of the aquifer. Formally,

$$
\frac{\partial w_{g}^{S}}{\partial \sigma}<0<\frac{\partial w_{r}^{S}}{\partial \sigma} \text { and } \frac{\partial h^{S}}{\partial \sigma}<0
$$

Proof of Proposition 5: The proof is relegated to the Appendix.

This result is very different from the one in Proposition 4. Non specialized farmers may react very differently to an increase in the subsidy on rainwater compared to specialized farmers. At the symmetric equilibrium with non specialized farmers, an increase in the subsidy on rainwater use may decrease the use of rainwater. When the farmers are not specialized, they use the two water sources (they "consume" the two "goods"), and rainwater may act like a Giffen good. Differently, when the farmers are specialized, they 
use only one water source (they "consume" only one "good"), then rainwater cannot act like a Giffen good.

In the case of non specialized farmers, an increase in the subsidy on rainwater use (a decrease in the "price" of rainwater), generates a positive substitution effect and an income effect (it is as if the recharge, $R$, were larger), which may be negative. When the income effect is negative and larger than the substitution effect, the farmers use less rainwater and more groundwater, which is the case in the linear-quadratic specification we considered. This goes along with a (relative) decrease in the cost of groundwater and with an increase in the level of the aquifer. In the case of specialized farmers (Proposition 4), since the farmers use rainwater only (they prefer to "consume" rainwater only), the income effect cannot be negative. As a result, at the asymmetric equilibrium with specialized farmers, an increase in the subsidy on rainwater use always increases the use of rainwater.

\section{Conclusion}

In this paper, we deal with the interactions between identical farmers who can choose between two water supplies (groundwater or rainwater). We characterize stationary symmetric and asymmetric equilibria and show that a subsidy on the use of rainwater may increase the use of rainwater and decrease the use of groundwater at the asymmetric equilibrium, whereas it may decrease the use of rainwater and increase the use of groundwater at the symmetric equilibrium. Moreover, the subsidy may increase the level of the aquifer at the symmetric equilibrium and decrease the level of the aquifer at the asymmetric equilibrium. Our results suggest that policies have to be designed in order to take into account how farmers coordinate as regards groundwater and rainwater use.

\section{Appendix}

\section{Proof of Proposition 4}

We first show a preliminary result. Since we focus on asymmetric equilibria with specialized farmers, we have $n_{g} \geq 1, n_{r} \geq 1$ and $n_{b}=0$. 
Lemma 1: Assume that $w_{r}^{A}$, the solution of $\max _{w_{r}}\left[F\left(\theta w_{r}\right)-C_{r}\left(w_{r}\right)\right]$, is positive and let $\bar{R} \equiv R-n_{r} w_{r}^{A}>0$. Also, assume that

$$
\begin{aligned}
\bar{V}_{g i}\left(h_{0}\right) & =\max _{w_{g i} \geq 0} \int_{0}^{\infty} e^{-\delta t}\left[F\left(\mu w_{g i}\right)-C_{g}\left(h, w_{g i}\right)\right] d t \text { for all } i \in G, \\
\dot{h} & =\rho \bar{R}-\sum_{i \in G} w_{g i}, \quad h(0)=h_{0} \text { given, }
\end{aligned}
$$

has a solution such that $w_{g i}^{A}(t)>0$ for all $i \in G$ and $h(t)>0$ for all $t$. Then, $w_{r i}=w_{r}^{A}$ for all $i \in R$ and $w_{g i}=w_{g i}^{A}$ for all $i \in G$ is a feedback equilibrium of our differential game.

Proof of Lemma 1: Suppose that a feedback equilibrium with $n_{g} \geq 1, n_{r} \geq 1, n_{b}=0$ and $h(t)>0$ exists. Let $V_{g i}$ be the value function of player $i$ in group $G$ and $V_{r i}$ the value function of player $i$ in group $R$. Let $\phi_{g i}$ be the feedback equilibrium strategy of groundwater use for player $i$ in group $G$ and $\phi_{r i}$ be the feedback equilibrium strategy $i$ in group $R$. These value functions are a solution of the following Hamilton-Jacobi-Bellman equations:

$$
\delta V_{g i}(h)=\max _{w_{g} \geq 0}\left[F\left(\mu w_{g}\right)-C_{g}\left(h, w_{g}\right)+\frac{\partial V_{g}(h)}{\partial h}\left(\rho\left(R-\sum_{j \in R} \phi_{g j}(h)\right)-w_{g}-\sum_{j \neq i} \phi_{g j}(h)\right)\right],
$$

and,

$$
\delta V_{r i}(h)=\max _{w_{r} \geq 0}\left[F\left(\theta w_{r}\right)-C_{r}\left(w_{r}\right)+\frac{\partial V_{r}^{i}(h)}{\partial h}\left(\rho\left(R-w_{r}-\sum_{j \neq i} \phi_{r}^{j}(h)\right)-\sum_{i} \phi_{g}^{i}(h)\right)\right] .
$$

Now, let us define the following strategies. Let $\phi_{r}=\arg \max _{w_{g}}\left[F\left(\theta w_{g}\right)-C_{r}\left(w_{g}\right)\right]$. We have

$$
\max _{w_{g}}\left[F\left(\theta w_{g}\right)-C_{r}\left(w_{g}\right)\right]=F\left(\theta \phi_{r}\right)-C_{r}\left(\phi_{r}\right)
$$

and

$$
\bar{V}_{r}=\int_{0}^{\infty} e^{-\delta t}\left[F\left(\theta \phi_{r}\right)-C_{r}\left(\phi_{r}\right)\right] d t=\frac{F\left(\theta \phi_{r}\right)-C_{r}\left(\phi_{r}\right)}{\delta}
$$

and $\bar{R}=R-n_{r} \phi_{r}$. Notice that $\phi_{r}$ is a constant and it does not depend on $h$. Also, $\bar{V}_{r}$ 
does not depend on $h$.

Let $\phi_{g}^{i}$ be the feedback Nash equilibrium strategy of player $i$ of the following differential game:

$$
\bar{V}_{g i}\left(h_{0}\right)=\max _{w_{g i} \geq 0} \int_{0}^{\infty} e^{-\delta t}\left[F\left(\mu w_{g i}\right)-C_{g}\left(h, w_{g i}\right)\right] d t, \quad \dot{h}=\rho \bar{R}-\sum_{j \in G} w_{g j}, \quad h(0)=h_{0} \text { given. }
$$

The associated HJB equation is

$$
\delta \bar{V}_{g i}(h)=\max _{w_{g i} \geq 0}\left[F\left(\mu w_{g i}\right)-C_{g}\left(h, w_{g i}\right)+\frac{\partial \bar{V}_{g}^{i}(h)}{\partial h}\left(\rho \bar{R}-w_{g i}-\sum_{j \neq i} \phi_{g}^{j}(h)\right)\right] .
$$

Suppose that the feedback Nash equilibrium is such that $h(t)>0$. Hence $\bar{V}_{g i}(h)$ and $\bar{V}_{g}$ (with the respective equilibrium strategies) are solutions of (38) and (39).

Now, we can establish the following result:

Lemma 2: There exists an asymmetric SNE with specialized farmers where an increase in the cost of rainwater (through an increase in $\sigma$ ) has the following effect:

$$
\frac{\partial w_{r}^{A}}{\partial \sigma}<0<\frac{\partial\left(\sum_{i \in G} w_{g i}^{A}\right)}{\partial \sigma}
$$

Moreover, we have $\frac{\partial h^{A}}{\partial \sigma}>0$ when $n_{g}=1$.

\section{Proof of Lemma 2:}

Let $C_{r} \equiv(1+\sigma) \widetilde{C}_{r}$. Using Lemma 1, we have $w_{r}^{A}=\max _{w_{r}}\left[F\left(\theta w_{r}\right)-(1+\sigma) \widetilde{C}_{r}\left(w_{r}\right)\right]$ and $\bar{R} \equiv R-n_{r} w_{r}^{A}$. Hence, when $\sigma$ increases, $w_{r}^{A}$ decreases and $\bar{R}$ increases. At the steady state, $\sum_{i \in G} \phi_{G i}=\sum_{i \in G} w_{g i}^{A}=\rho \bar{R}$, and then $\sum_{i \in G} w_{g i}^{A}$ increases with $\sigma$. If all the players in group $G$ use the same level of groundwater, then $w_{g i}^{A}$ increases with $\sigma$.

Now, let us focus on the case in which $n_{g}=1$. Since $w_{r}^{A}$ does not depend on $h$, we have $\delta_{i}(h)=\delta$ for $i \in G$. Let us show that $\frac{\partial h^{A}}{\partial \sigma}>0$. We first show that $\frac{\mu}{\theta}>\frac{1}{\rho}$. Let $R C_{i} \equiv M C_{g i}\left(h, w_{g i}\right) / M C_{r i}\left(h, w_{g i}, w_{r i}\right)$ denote the ratio of marginal costs, where

$$
M C_{g i}\left(h, w_{g i}\right) \equiv \frac{\partial C_{g}}{\partial w_{g}}\left(h, w_{g i}\right)-\frac{1}{\delta_{i}(h)} \frac{\partial C_{g}}{\partial h}\left(h, w_{g i}\right),
$$


and,

$$
M C_{r i}\left(h, w_{g i}, w_{r i}\right) \equiv C_{r}^{\prime}\left(w_{r i}\right)-\rho \frac{1}{\delta_{i}(h)} \frac{\partial C_{g}}{\partial h}\left(h, w_{g i}\right) .
$$

Let $w_{g}^{A} \equiv w_{g i}^{A}$. Using condition (30), condition (33) and because the ratio of

the marginal costs is a decreasing function of $w_{r i}$, we have

$$
\frac{M C_{g}\left(h, w_{g}^{A}\right)}{M C_{r}\left(h, w_{g}^{A}, 0\right)} \leq \frac{\mu}{\theta}<\frac{M C_{g}(h, 0)}{M C_{r}(h, 0,0)}
$$

Note that this implies that it is not possible $\frac{M C_{g}\left(h, w_{g}\right)}{M C_{r}\left(h, w_{g}, 0\right)} \geq 0$ for all $w_{g} \in\left[0, w_{g}^{A}\right]$ (because if it is the case $\left.w_{g}^{A}<0\right)$. Then there must exist $\widetilde{w}_{g} \in\left[0, w_{g}^{A}\right]$ such that the derivative of the ratio of marginal cost, $\frac{M C_{g}\left(h, \widetilde{w}_{g}\right)}{M C_{r}\left(h, \widetilde{w}_{g}, 0\right)}$ is negative. Notice that this derivative is:

$$
\begin{gathered}
\frac{\left(\begin{array}{c}
{\left[\frac{\partial^{2} C_{g}}{\partial w_{g}^{2}}\left(h, \widetilde{w}_{g}\right)-\frac{1}{\delta} \frac{\partial^{2} C_{g}}{\partial w_{g} \partial h}\left(h, \widetilde{w}_{g}\right)\right]\left[C_{r}^{\prime}(0)-\rho \frac{1}{\delta} \frac{\partial C_{g}}{\partial h}\left(h, \widetilde{w}_{g}\right)\right]} \\
+\rho \frac{1}{\delta} \frac{\partial^{2} C_{g}}{\partial w_{g} \partial h}(h, \tilde{g})\left[\frac{\partial C_{g}}{\partial w_{g}}\left(h, \widetilde{w}_{g}\right)-\frac{1}{\delta} \frac{\partial C_{g}}{\partial h}\left(h, \widetilde{w}_{g}\right)\right]
\end{array}\right)}{\left[C_{r}^{\prime}(0)-\rho \frac{1}{\delta} \partial_{h} C_{g}\left(h, \widetilde{w}_{g}\right)\right]^{2}} \\
=\frac{\frac{\partial^{2} C_{g}}{\partial w_{g}^{2}}\left(h, \widetilde{w}_{g}\right)\left[C_{r}^{\prime}(0)-\rho \frac{1}{\delta} \frac{\partial C_{g}}{\partial h}\left(h, \widetilde{w}_{g}\right)\right]-\frac{1}{\delta} \frac{\partial^{2} C_{g}}{\partial w_{g} \partial h}\left(h, \widetilde{w}_{g}\right)\left[C_{r}^{\prime}(0)-\rho \frac{\partial C_{g}}{\partial w_{g}}\left(h, \widetilde{w}_{g}\right)\right]}{\left[C_{r}^{\prime}(0)-\rho \frac{1}{\delta} \frac{\partial C_{g}}{\partial h}\left(h, \widetilde{w}_{g}\right)\right]^{2}} .
\end{gathered}
$$

Hence, we must have

$$
C_{r}^{\prime}(0)-\rho \frac{\partial C_{g}}{\partial w_{g}}\left(h, \widetilde{w}_{g}\right)<-\frac{\frac{\partial^{2} C_{g}}{\partial w_{g}^{2}}\left(h, \widetilde{w}_{g}\right)}{-\frac{1}{\delta} \frac{\partial^{2} C_{g}}{\partial w_{g} \partial h}\left(h, \widetilde{w}_{g}\right)}\left[C_{r}^{\prime}(0)-\rho \frac{1}{\delta} \frac{\partial C_{g}}{\partial h}\left(h, \widetilde{w}_{g}\right)\right]<0 .
$$

Using (45) and $\frac{\partial^{2} C_{g}}{\partial w_{g}^{2}} \geq 0$, we have

$$
\frac{1}{\rho} C_{r}^{\prime}(0)-\frac{\partial C_{g}}{\partial w_{g}}\left(h, w_{g}^{A}\right)<\frac{1}{\rho} C_{r}^{\prime}(0)-\frac{\partial C_{g}}{\partial w_{g}}\left(h, \widetilde{w}_{g}\right)<0 .
$$

This implies

$$
\frac{M C_{g}\left(h, w_{g}^{A}\right)}{M C_{r}\left(h, w_{g}^{A}, 0\right)}=\frac{1}{\rho} \frac{C_{g}\left(h, w_{g}^{A}\right)-(1 / \delta) \frac{\partial C_{g}}{\partial h}\left(h, w_{g}^{A}\right)}{C_{r}^{\prime}(0) / \rho-(1 / \delta) \frac{\partial C_{g}}{\partial h}\left(h, w_{g}^{A}\right)}>\frac{1}{\rho},
$$


Using (44), we have $\frac{\mu}{\theta}>\frac{1}{\rho}$.

Differentiating (28) with respect to $\sigma$, we have

$\left[\frac{1}{\delta} \frac{\partial^{2} C_{g}}{\partial h^{2}}\left(h, w_{g}^{A}\right)-\frac{\partial^{2} C_{g}}{\partial w_{g} \partial h}\left(h, w_{g}^{A}\right)\right] \frac{\partial h}{\partial \sigma}=\left[\frac{\partial C_{g}}{\partial w_{g}}\left(h, w_{g}^{A}\right)-\frac{1}{\delta} \frac{\partial^{2} C_{g}}{\partial w_{g} \partial h}\left(h, w_{g}^{A}\right)-\mu^{2} F^{\prime \prime}\left(\mu w_{g}^{A}\right)\right] \frac{\partial w_{g}^{A}}{\partial \sigma}$

Finally, $\frac{\partial h^{A}}{\partial \sigma}>0$.

Moreover, in the quadratic linear specification with two players, the SNE with specialized farmers is unique.

\section{Proof of Proposition 5}

We focus on the SNE in which the two farmers use rainwater and groundwater. Assuming that the two farmers use linear strategies, i.e. that farmer $i$ considers that player $j$ uses $w_{g j}=a_{g} h+b_{g}$ and $w_{r j}=a_{r} h+b_{r}$ and that the value function is quadratic $V(h)=$ $\frac{A}{2} h^{2}+B h+C$. The farmer has to solve the following problem:

$\delta V(h)=\max _{w_{r}, w_{g}}\left[F\left(\mu w_{g}+\theta w_{r}\right)-(c-h) w_{g}-K w_{r}+\frac{\partial V(h)}{\partial h}\left(\rho\left(R-w_{r}-a_{r} h-b_{r}\right)-w_{g}-a_{g} h-b_{g}\right)\right]$.

For this case, first order condition gives:

$$
\mu-\left(\mu w_{g}+\theta w_{r}\right) \mu-c+h-A h-B=0, \quad \theta-\left(\mu w_{g}+\theta w_{r}\right) \theta-K-(A h+B) \rho=0,
$$

from these two equations we obtain

$$
\frac{\mu}{\theta}=\frac{c-h+A h+B}{K+(A h+B) \rho}
$$

This states that the solution is singular solution because $h$ does not depend on time. ${ }^{12}$ Hence, in equilibrium, we must have $A=B=0$ and $\dot{h}=0$. The unique steady state is

\footnotetext{
${ }^{12}$ Also note that the optimal levels of $h, w_{g}, w_{r}$ are constant. If $h_{0}=h$ the optimal solution is to keep $\dot{h}(t)=0$, for all $t$. If this is not the case, it remains to study the transitory path.
} 
characterized by:

$$
h^{S}=c-\frac{\mu}{\theta} K, \quad w_{g}^{S}=\frac{\rho\left(\theta-K-\frac{\theta^{2} R}{2}\right)}{\theta(\rho \mu-\theta)}, \quad w_{r}^{S}=\frac{-\theta+K+\frac{\theta \mu \rho R}{2}}{\theta(\rho \mu-\theta)} .
$$

We can easily deduce that

$$
\frac{\partial h^{S}}{\partial \sigma}=\frac{\partial h^{S}}{\partial K}<0
$$

and

$$
\frac{\partial w_{r}^{S}}{\partial \sigma}=\frac{\partial w_{r}^{S}}{\partial K}=-\frac{1}{\rho} \frac{\partial w_{g}^{S}}{\partial K}
$$

Moreover

$$
w_{g}^{S}=\rho \frac{\mu+h-c-\frac{\theta \mu R}{2}}{\mu(\rho \mu-\theta)}, \quad w_{r}^{S}=\frac{-\mu+c-h+\frac{\mu^{2} \rho R}{2}}{\mu(\rho \mu-\theta)},
$$

with

$$
\frac{\partial w_{g}^{S}}{\partial h}=\frac{1}{\mu(\rho \mu-\theta)}, \quad \frac{\partial w_{r}^{S}}{\partial h}=-\frac{1}{\mu(\rho \mu-\theta)} .
$$

One can check that $w_{g}^{S}, w_{r}^{S}>0$ implies $\rho \mu-\theta>0$. Hence $\frac{\partial w_{g}^{S}}{\partial \sigma}=\frac{\partial w_{g}^{S}}{\partial h} \frac{\partial h^{S}}{\partial \sigma}<0$ and $\frac{\partial w_{r}^{S}}{\partial \sigma}=\frac{\partial w_{r}^{S}}{\partial h} \frac{\partial h^{S}}{\partial \sigma}>0$.

\section{References}

[1] Burt O.R., (1964), The economics of conjunctive use of ground and surface water, Hilgardia, 36(2), p.31-111.

[2] Chakravorty U. and Umetsu C., (2003), Basinwide water management: a spatial model, Journal of Environmental Economics and Management, 45, p.1-12.

[3] Cummings R. G., (1971), Optimum exploitation of groundwater reserves with saltwater intrusion, Water Resources Research, 7(6), p.1415-1424.

[4] Dockner E.J., Jorgensen S., Long N. V. and Sorger G., (2000), Differential games in economics and management science, Cambridge University Press, 350p. 
[5] Gemma M. and Tsur Y., (2007), The stabilization value of groundwater and conjunctive water management under uncertainty, Review of Agricultural Economics, 29(3), p.540-548.

[6] Gisser M. and Sanchez D.A., (1980), Competition versus optimal control in groundwater pumping, Water Resources Research, 31, p.638-642.

[7] IPCC, Climate Change (2007), Synthesis Report, Geneva, Switzerland, 104p.

[8] Johnson, N., Revenga C. and Echeverria J., (2001) Managing Water for People and Nature, Science, 11, 292 (5519), p. 1071-1072.

[9] Knapp K.C. and Olson L.J, (1995), The economics of conjunctive groundwater management with stochastic surface supplies, Journal of Environmental Economics and Management, 28, p.340-356.

[10] Koundouri P., (2004), Current issues in the economics of groundwater resource management, Journal of Economic Surveys, 18(5), p.703-740.

[11] Krulce D. L., Roumasset J.A. and Wilson T., (1997), Optimal management of a renewable and replacable Resource: The case of coastal groundwater, American Journal of Agricultural Economics, 79, p.1218-1228.

[12] Moreaux M. and Reynaud A., (2004), Optimal management of a coastal aquifer and a substitute resource, Water Resources Research, 40, p.1-10.

[13] Moreaux M. and Reynaud A., (2006), Urban freshwater needs and spatial cost externalities for coastal aquifers: A theoretical approach, Regional Science and Urban Economics, 36, p.163-186.

[14] Negri D.H., (1989), The common property aquifer as a differential game, Water Resources Research, 25(1), p.9-15.

[15] Ostrom E., (1990), Governing the commons - The evolution of institutions for collective action, Cambridge University Press, New York. 
Author-produced version of the article published in Environmental and Resource Economics, 2015, N62(1), p. 19-34.

[16] Pandey D. N., (2001), A Bountiful Harvest of Rainwater, Science, 7, 293 (5536), 1763.

[17] Pongkijvorasin S. and Roumasset J., (2007), Optimal conjunctive use of surface and groundwater with recharge and return flows: dynamic and spatial patterns, Review of Agricultural Economics, 29(3), p.531-539.

[18] Roseta-Palma C., (2003), Joint quantity/quality management of groundwater, Environmental and Resource Economics, 26, p.89-106.

[19] Roumasset J.A. and Wada C.A., (2012), Ordering the extraction of renewable resources: The case of multiple aquifers, Resource and Energy Economics 34, p.112128.

[20] Rowat C., (2002), Asymmetric play in a linear quadratic differential game with bounded controls. Working Paper 02-12, University of Birmingham, Department of Economics, 2002.

[21] Rubio S.J. and Casino B., (2001), Competitive versus efficient extraction of a common property resource: the groundwater case, Journal of Economic Dynamics and Control, 25, p.1117-1137.

[22] Rubio S.J. and Casino B., (2003), Strategic behavior and efficiency in the common property extraction of groundwater, Environmental and Resource Economics, 26(1), p.73-87.

[23] Stahn H. and Tomini A., (2009), A drop of rainwater against a drop of groundwater: does rainwater harvesting really spare groundwater?, DT GREQAM 2009-43.

[24] Stahn H. and Tomini A., (2011), Rainwater harvesting under endogenous capacity of storage: a solution to aquifer preservation?, Annals of Economics and Statistics.

[25] Tsur Y. and Graham-Tomasi T., (1991), The buffer value of groundwater with stochastic surface water supplies, Journal of Environmental Economics and Management, 21, p.201-224. 
Author-produced version of the article published in Environmental and Resource Economics, 2015, №2(1), p. 19-34. The original publication is available at http://link.springer.com

Doi: 10.1007/s10640-014-9813-9

[26] Zeitouni N. and Dinar A., (1997), Mitigating negative water quality and quality externalities by joint management of adjacent aquifers, Environmental and Resource Economics, 9, p.1-20. 